\title{
Luck Egalitarianism, Individual Responsibility and Health
}

\author{
Perihan Elif Ekmekçi ${ }^{1}$, Berna Arda $^{2}$ \\ ${ }^{1}$ Ministry of Health, Ankara, Turkey \\ ${ }^{2}$ Department of History of Medicine and Ethics, Ankara Univeristy Faculty of Medicine, Ankara, Turkey
}

Luck Egalitarianism has frequently been discussed in the recent literature because of the potential impact of this theory on health financing. Luck Egalitarianism puts forth a theory of distributive justice which says that the fundamental aim of equality is to compensate people for undeserved bad luck such as being born with poor native endowments, having difficult family circumstances or suffering from accidents and illness. On the other hand, if individuals face ill health because of faults of their own, then society has no duty to supply health services to them.

Many arguments for and against this theory have been raised since it was first introduced. The proponents of Luck Egalitarianism focus on the concepts that free choice and respecting the autonomy of the individual determine whether health services are deserved. The criticisms against the concept of Luck Egalitarianism are that it is harsh to the needy and abandons the wretched, discriminates against the disabled, is against basic humanitarian principles, is incompatible with human dignity, and is in dissonance with real life.

We agree with the basic proposition of Luck Egalitarian theory, which states that "inequalities deriving from unchosen features of people's circumstances are unjust and therefore should be compensated for". Our agreement leads us to an opposite conclusion. We propose that the "unchosen features of people's circumstances" include more than personal disadvantages. The social features to be included in the context of inequalities deriving from unchosen features of peoples circumstances are, socioeconomic status (SES), access to social determinants of health, and the ethnic, cultural and religious identity of individuals. Our other propositions are the mutable character of choices which makes individual responsibility of preferences implausible; the problematic causal relationship between responsibility and ill-health; the disregard of the motives behind decisions; problems with implementation in real health service circumstances; and the contradictory nature of Luck Egalitarianism for principles of medical ethics. These arguments draw attention to possible ethical and practical consequences of implementation of health policies arising from Luck Egalitarian view for patients and for health care providers. In this paper, we will first define Luck Egalitarianism. Then, we will discuss arguments for and against the theory in the literature. Our final task is to suggest additional criticisms of the theory and justify them.

Keywords: Distributive justice, fundamental causal theory, group norms, health inequalities, individual responsibility, luck egalitarianism, medical ethics, social determinants of health
Basic ethical theories have various attitudes towards right to health. Utilitarian ethical theory states that it is ethically obligatory to act in a way which would create the most utility/ happiness for the majority of the population. Thus, utilitarian perspective regards rights to health as a tool to achieve utility/happiness of the majority. In this view, health is not recognized as a fundamental human right with intrinsic ethical value but rather a means to the utmost good which is utility/ 
happiness. Libertarian ethical theory has a different justification to regard right to health as conditional instead of fundamental. In the libertarian ethical perspective, right to health is not different from the right to have other goods or services. An individual has the right to access health services if she pays for them; health has no special ethical value and should be subject to the rules of market. Buying health services is like buying a car or purchasing a car cleaning service.

John Rawls theory of justice and Amartya Sen's "capacity approach" evoked attempts to justify right to health. Rawls theory has left health out of the two principles of a fair society; some theories are produced to extend his theory to cover health. Likewise, Sen's capability approach is regarded as a basis to justify the obligation of the governments to provide the health needs of each and every individual. However all these attempts prove the fact that some sound ethical theories consider right to health not an absolute fundamental human right but rather a relative conditional provision.

Furthermore, practical life proves this perception. Right to health is among the fundamental human rights and is recognized in international agreements such as the International Covenant on Civil and Political Rights and the International Covenant on Economic, Social and Cultural Rights. Although many countries in the UN have signed these international covenants, the right to health is hardly regarded as indispensable to realize human rights. This arises from the common approach of governments to social and cultural rights. These rights are positive human rights; thus, they have to be provided by the governments to the citizens. The limited resources and the budgetary scantiness create an excusable alibi to limit right to health to a certain extent.

These theoretical and practical grounds reveal the plausibility of limiting access to health services. Luck egalitarianism is among the ethical theories that require a precondition to be met to have access to health services: the prudency of the individual.

\section{LUCK EGALITARIAN VIEW On HEALTH}

Individuals' lifestyles have a significant impact on the risks and burden of diseases that they are likely to face throughout their lives. Luck Egalitarians suggest that a person's lifestyle consists of the choices that the individual makes throughout her life. She should be held responsible for her own decisions and should bear the benefits and burdens of her choices. If an individual loses her health as a result of her lifestyle choices, she should be held responsible for the consequences, not any other person or institution. Thus, society does not owe her any health service or assistance (1).
On the other hand, an individual may face health risks or may lose her health through no fault of her own. This means that a person may have undesirable health status because of bad luck not because of her own choices. Luck Egalitarianism suggests unchosen circumstances cannot justify inequalities. Therefore, we own individual compensation for aspects of their disadvantaged status which they have not chosen. Society should make sure that they have access to the health services they need $(1,2)$.

Luck Egalitarianism puts forward the idea that if agents are not truly responsible for their actions it is implausible to blame or penalize them for their current state as they have the problem through no fault of their own. If the people who face health problems due to their own choices were not given priority or if they were not financed by a common system, then the people whose behavior has not contributed to cause their ill-health would have a greater chance of being cured.

In general, Luck Egalitarians think that it is unjust for people to get a lesser share of health services due to things outside of their control and unchosen circumstances cannot justify health inequalities. This rationale is grounds for the impact of prudent decisions on the health of people. If a person behaves prudently and takes steps which should lead to good health status but ends up getting ill, that person should not be held responsible for causing the illness and society owes her treatment $(1,3)$.

In other words, Luck Egalitarianism claims a theory of distributive justice which says that the fundamental aim of equality is to compensate people for undeserved bad luck such as being born with poor native endowments, having difficult family circumstances or suffering from accidents, illnesses and so forth (4).

Luck Egalitarians make a distinction between choice and luck. They label this distinction "option-luck" and "bruteluck". If an individual takes prudent actions for health but ends up with ill-health, Luck Egalitarians call this "brute luck". Brute-luck is a category in which society owes her compensation for ill-health because it occurs through reasons beyond her control. Option-luck is where she is considered to have chosen a consequence by her imprudent behavior. If an individual acts imprudently by taking risks regarding her health and becomes ill, she has made her own choice. She had the option of doing things differently but she did not. Society owes her compensation or access to health care because it occurred through reasons within her control $(4,5)$.

\section{ARGUMENTS SUPPORTING LUCK EGALITARIANISM}

The arguments in support of Luck Egalitarianism, mainly focuses on the concepts of deserving, wronging people, respect to human autonomy and individual responsibility. 
Luck Egalitarians claim that taking away goods from the deserving for the sake of the undeserving is unjust. The individuals who gained goods through hard work and prudent behavior do not have any moral obligation to make up for those who happen to find themselves in a worse situation. Demanding the opposite of this would undermine personal responsibility by guaranteeing outcomes independent of individual choices which would end up supporting laziness, unwillingness to work and would penalize the hard-working (3). This not only distorts the notion of justice in society but also ruins any motivation to be more productive and to push hard to produce maximum possible achievements.

Another argument in favor of Luck Egalitarianism is derived from the same concept of taking away from the deserving but develops in another way. This argument places emphasis on the concept of wronging people. It proposes that if you put the financial burden of the imprudent on the prudent, you wrong both of them. The prudent individual has behaved responsibly and made the right choices with the expectation of having priority and the right to get health services whenever she needs them. By taking away some of her benefits and shifting them to individuals who have not done what they were supposed to do, you wrong her. Also, you wrong the imprudent. Individuals may tend to act more prudently if they are aware of the fact that they will have to pay for all the possible bad consequences of their choices and nobody will be there to help them. Then, they would think twice before refusing to pay for the health insurance or committing risky behaviors such as smoking, extreme sports or drug use. By taking away the opportunity to feel and act fully responsibly, you impel them to act imprudently. This may also be considered as being insolent and disrespectful to human dignity and human autonomy (5).

The proponents of Luck Egalitarianism defend their view in various ways against the critique of harshness. They tend to accept that the classical luck egalitarian view which does not make a distinction between brute luck and that option luck is open to the harshness criticism. They state that option luck egalitarianism is immune to this critique as it takes its origins from deliberate and calculated gambles. As the individual who prefers to smoke or undertake extreme risky sports is willing to taste the pleasure they will give to her, she must be ready to suffer and feel the pain if things go wrong. Nobody or no institution interferes with her free will and her autonomy while she is making this decision as a show of respect to her dignity. Therefore, why should they have to interfere when risk is realized instead of pleasure? Defining this reasonable end as "harshness" invites an emotional dimension to the argument which tends to appeal to the feeling of people instead of their minds; thus, it may not be a plausible way of ethical reasoning.
Others defend the theory by stepping back and saying that Luck Egalitarianism is an argument which explains why it is unjust to be worse off than others because of brute luck and offers a way of distributive justice to protect the rights of deserving ones. They come up with a new assertion which says Luck Egalitarianism is a weak theory and should be complemented by other moral considerations to avoid the undesired consequences such as abandonment of human beings. A very similar but more pretentious argument states that Luck Egalitarianism is a strong theory, because it shows us universal ideal justice, which may be beyond human understanding at any given time. They argue that we may need to choose the second best option instead of the ideal theory because of the limits of human understanding (6). They refer to a sphere of ideal distributive justice like the concept spheres of Plato hanging on space and they suggest the need to modify the ideal justice of Luck Egalitarianism to the limits of current human understanding.

The criticism of abandonment of the undeserving is refuted by the proposal of a minimum income provided to anyone. Another suggestion is that governments should make paternalistic decisions $(4,5)$. The rationale behind this is to make obligatory rules so that prudent decisions are made for everyone. There will be no one left to be called imprudent. This suggestion is often supported by the legislative function of governments. The opponents of this view point out the paternalistic nature of this approach. It is also considered disrespectful towards human autonomy and dignity, which is ironic, as these are supposed to be the values that Luck Egalitarians weight the most.

According to Luck Egalitarians, justice is not the only value that lies behind the belief that people should be held responsible for their own decisions and behaviors. Respect for human dignity and autonomy also plays a significant role. Luck Egalitarians generally reject any paternalistic attitude. They claim that individuals should decide according to their own free will and no one or no institution should interfere during the decisionmaking process. Therefore, individuals should bear the consequences of their decisions no matter the personal cost. However, this emphasis on personal cost triggers opposition from those who view the focus on free will as an excuse to abandon the least fortunate. Despite the Luck Egalitarians' usual rejection of government intervention, there is some acceptance of the legislative function of the government to avoid costly imprudent decisions. Luck Egalitarians say that to be patronized is a fair price to pay for imprudent adults when they are not grown up enough to take the responsibility for their own faults.

\section{ARGUMENTS AGAINST LUCK EGALITARIANISM}

The rise of the Luck Egalitarian approach in political philosophy has been significant in recent years. The impact of 
this idea on health economics has contributed to make it a compelling issue for many governments, health insurance companies and health service providers. Because of its potential economic impact, Luck Egalitarianism is currently being discussed widely.

The disputes against Luck Egalitarianism are various. The concepts they mainly argue are harshness towards the needy and abandonment of the wretched, discrimination of the disabled, anti-humanitarianism, incompatibility with human dignity, and dissonance with real life.

The most well-known argument against Luck Egalitarianism's harshness is raised by Elisabeth S. Anderson (5). She states that Luck Egalitarians do not support assistance for those who choose to live in areas of hurricane or earthquake, take risky jobs, be faulty drivers and involve in accidents and so on. By claiming that it is the individual's own responsibility to pay for their own inaccuracies, they turn a blind eye to all inequalities that reflect a choice in some way, irrespective of the degree of individual responsibility. This results in the exploitation and abandonment of the wretched. Anderson says that true egalitarian justice does not allow the exploitation of human beings even if they were imprudent. She underscores this idea by saying that the real point of egalitarian equality is the idea of being free from oppression, which is achieved by "democratic equality". She defines democratic equality as "everybody is entitled to the capabilities required to live as human beings pursuing their own concepts of good avoiding oppressive and exploitative social relationships and participating in the social, economic and political life of their communities" $(5,6)$. I wish to add the phrase "irrespective of their background, behaviors, choices and socioeconomic status (SES) or any other feature" to the end of this definition.

Another criticism for Luck Egalitarianism is that it discriminates between disabled people. An individual who is held responsible for her disability will not get any assistance while a person who has the same the disability but is considered innocent of causing the disability will get assistance. The idea of treating two people with the same disabilities differently depending on their past decisions does not seem to be in compliance with justice and may be named absolute discrimination. The supporters of this idea advance their claim by saying that this discriminatory attitude not only applies to the disabled but to all vulnerable people. In this respect, Luck Egalitarianism inevitably results in geographical and occupational discrimination (5). Luck Egalitarianism denies compensation to stay at home care takers stating that they made this choice by their own free will than not because other options were not open to them.

The argument of anti-humanitarianism is raised for victims of brute luck. Those individuals who are found to be entitled to compensation for their disadvantages because of brute luck are determined by a comparison process which does not involve humanitarian compassion but pity (5). This point may be explained by referring to objective criterion called "indominated diversity". This criterion depends on comparing the internal assets of two individuals. If one of them is found to have preferable internal assets to the other, then the one with disadvantage deserves compensation. Anderson criticizes this approach because the concept of eligibility of compensation is grounded in the assumption of inferiority. The assumption that some people are inferior to others points not to humanitarian concerns but to concerns of pity $(5,7,8)$. The discourse of compensation is viewed as disrespect to vulnerable and/or disabled human beings because it implies that able people are superior.

Another significant objection to Luck Egalitarianism depends on the concept of sheer-luck. The supporters of this idea state that, when two individuals take the same risk by making the same choice, one may end up failing and realizing the risk and the other may not. Therefore, the determining factor of this consequence seems to be not the choice but "sheer-luck" (6). This makes the "action of choice" morally arbitrary as an explicit causality cannot be justified. This view undermines the responsibility of individuals and upgrades the victims of option luck to the level of victims of brute luck in respect to eligibility of compensation.

A consequentialist criticism of Luck Egalitarianism uses a slippery slope argument to propose that the Luck Egalitarian approach may lead to broad catastrophes. They begin with challenging the scope of the Luck Egalitarian argument; if we hold individuals responsible for the ends of their choices, then we should hold every decision-making agent responsible in the same way. Governments are decision-making agents. Following this line of thinking, if a government makes decisions which lead to poverty and/or suffering of their citizens, the rest of the world, including international organizations, does not owe help to citizens of that country (5). This may lead to enormous harm for humanity. Consider the victims of a severe earthquake. According to this view, the rest of the world is not morally obliged to help them claiming that they should have built safe apartments, offices and schools beforehand. By doing the opposite, the country took the risk and should not be assisted.

The process of decision-making has been an attractive subject for anti-Luck Egalitarians. They defend their point by saying that an individual may not be fully informed about the potential risks involved in a particular decision which absolves her responsibility or may reduce the proportionality of her responsibility if the risk is realized. This criticism may not be counted as a criticism in the ethical scope, as it does not 
oppose the values behind the idea but refers to problems of practicality. While it is not an ethical argument nonetheless considering access to information is essential, if Luck Egalitarianism is to be taken as a basis for implementation of health service financing (8).

Another criticism of Luck Egalitarianism regarding decision-making is the determinative role of social circumstances on lifestyle choices. The proponents of this claim say that the choices people make are determined by their social circumstances. It is impossible to apportion the amount of decisionmaking responsibility between social influences and individual will. This will be discussed further in connection with the concept of impact of social norms on the decision-making process.

\section{NEW CONSIDERATIONS}

We would like to discuss some other objections against Luck Egalitarianism based on the narrow definition of health, social factors beyond individual's control, the mutable character of choices which makes individual responsibility of preferences implausible, weak causality between one time decisions and ill-health, ignorance of motives behind the decisions and contradictory position of the theory to medical ethics principles. In addition weighting degrees of individual choice in the context of a medical emergency is not practical.

Luck Egalitarianism conceptualizes health from a narrow point of view. The tendency is to consider health as something that can be lost or gained by one decision. Contemporary research shows the opposite. The causal relationship between diseases and one-time choice is weak. When a patient arrives in the emergency room with a heart attack, the story behind this attack has been written throughout his life (9). The factors that have a significant impact throughout a life are rarely one or two particular decisions, but the living and working conditions which are not mostly determined by him.

The definition of Luck Egalitarianism states that "the inequalities deriving in health from unchosen features of peoples circumstances are unjust and therefore should be compensated" (5). We totally agree with this view. However this agreement leads us to an opposite conclusion than Luck Egalitarianism. We propose that the "unchosen features of people's circumstances" include more than personal disadvantages. Luck Egalitarians believe that individual choices have a core role in health status. We propose instead that the social determinants of health are of central importance to an individual's health status. These social determinants are beyond an individual's control.
To explain our view, we will discuss what the "inequalities in health deriving from the unchosen features of people's circumstances" may be. The first and most fundamental unchosen circumstance consists of the social milieu into which the individual is born. The social environments we are considering for this paper are SES, cultural attitudes towards health and ethnicity. These are aspects of the natural lottery which can lead to a promising start to life for some people while pushing others far behind the starting line. We do not mean this from in a passive fatalistic perspective which says that we are all victims of our circumstances. On the contrary, what we emphasize is the enormous impact that cultural values, ethnicity and SES have on individuals throughout the course of their lives. Awareness of this impact gives societies/governments the opportunity to develop policies to address these disadvantages.

Luck Egalitarians define natural lottery as the personal talents and abilities a person has from the start of their lives. This is a narrow view, which excludes the social factors that affect the individual and are beyond the individual's control. Luck Egalitarians are in favor of compensating the disadvantages arising from personal inferiorities such as a low IQ, genetic physiological and physical diseases, developmental disorders and so on. We agree that these are major challenges an individual may find very hard to overcome to have a normal life; therefore, they should be compensated. What we want to draw attention to are those people who do not have any of the aforementioned personal barriers, who are definitely healthy when they are born. These individuals are among the people who are considered to be lucky in the natural lottery by the Luck Egalitarians, but in fact their story is totally different. Being born healthy does not necessarily lead to staying healthy throughout life.

One of the arguments which supports our view is the fundamental causal theory developed by Link and Phelan $(10,11)$. Fundamental causal theory puts forth the idea that the SES of people has a huge impact on their health status. They explore the socioeconomic pattern of ill-health throughout history. According to Link and Phelan, the people who live in the lowest SES have historically been vulnerable to mortality and morbidity of most diseases. People in the lowest SES have consistently had significantly shorter longevity than the general population. Some epidemiologic studies claim that the relationship between SES and health status is a confounding variable correlation rather than a causal relationship. Phelan and Link state that the SES of individuals is the fundamental cause which starts the chain of events leading to high mortality and morbidity (10).

The pattern of death during the plagues of the Middle Age often referred to as the Black Death pandemic is a historic ex- 
ample. The Black Death pandemic mostly killed populations living in poverty in Europe and the Ottoman Empire. While some of the victims of this malady belonged to the aristocracy, the huge number of deaths was mostly from the lowest SES level of the population. We see the same pattern today. The modern Black Deaths of our time such as chronic diseases, infectious diseases and injuries affect people from a lower SES disproportionately compared to people who are from a higher SES (12). Thus, although the causes of mortality and morbidity change over time and although we have new innovative ways of coping with diseases, this causal relation remains constant throughout history.

Link and Phelan set forth the fundamental causal relationship grounds of the advantages which higher SES conveys to individuals such as income, knowledge, prestige, power and benefiting social relationship $(11,13)$. Social determinants of health such as education, housing, employment, and health insurance are differential advantages depending on the individual's SES (12). A higher SES level enhances both the quantity and quality of all of these individual and social factors which not only apply to the prevention of diseases but also to the treatment process after the illness occurs.

According to this theory, a fundamental cause of mortality has four common features; " 1 . It influences multiple disease outcomes, 2. It affects these outcomes thorough multiple risk factors, 3. The association between the fundamental cause and mortality is reproduced over time via the replacement of intervening mechanisms, and 4 . The essential feature of fundamental causes is that they involve access to resources that can be used to avoid risks or to minimize the consequences of disease once it occurs" (13). There are data to support the first two propositions. A lower SES is known to be strongly associated with risk factors such as smoking, a sedentary life-style, obesity, social isolation, unsanitary water supplies, and malnutrition. According to a World Health Organization (WHO) report on the social determinants of health, these are the major risk factors for the top ranked burden of disease and causes of mortality (12). The third precondition is proved by "the historical evidence which shows that there has been a consistently strong SES gradient in mortality at least since early $19^{\text {th }}$ century and that dramatic changes in the risk factors linking SES and mortality have occurred over this time." (13). Also there is significant evidence showing that the SES gradients, in particular risk factors and outcomes of diseases, have changed, as predicted by the theory. Smoking is a good example of the realization of this prediction. When the causal link between smoking and chronic diseases became clear, the smoking rate among higher SES groups declined dramatically. Since the decline in tobacco use, the burden of disease caused by smoking such as lung cancer and coronary artery diseases has dropped significantly among high SES individuals. The individual and social benefits of resources which become available by the high SES prove that the fourth proposition is fulfilled as well, although "empirically testing the importance of these resources per se is difficult, because it requires the identification of situations in which the ability to use SES resources can be analytically separated from SES itself'(13,14).

The fundamental causal theory is also supported by the results of the Whitehall Study pursued by Michael Marmot. In his research, Marmot revealed the steep health gradients observed among the British civil servants depending on their SES, for mortality rates, longevity and also for morbidity rates across a range of diseases (15). His study has served as a baseline for the formation of a Committee on Social Determinants of Health by WHO, which recognized the social determinants of health as a major factor of health (16).

The other unchosen social factors which have a direct impact on health are the ethnic, cultural and/or religious identity of the individual. Most of the ethnic, cultural or religious groups set their own norms and these norms may not necessarily be consistent with the norms of the majority of the population. In fact, having different norms is a major factor that defines group identity. Therefore, an individual who belongs to a specific minority group responds to her group norms when making a decision rather than the norms of the majority. The outcome of this particular decision-making process may be viewed as irresponsible or irrational by the majority of the population which responds to different norms. One may oppose this idea by claiming that each individual has her own free will and thus has the ability to find out what's good or bad by her autonomy without necessarily referring to social norms and values. Although some may consider this a true proposition in theory, the practice is not always in agreement with this.

What we discuss for the minorities is also valid for the rest of the societies. The philosophers in support of social contract theory state that individuals decided to abandon some of their freedoms in order to enjoy the safety of living together and to minimize the threats of chaos. What holds societies, including minorities, together is this willingness to stay together. This togetherness depends on common values and norms. Individuals who are born into society are raised by these norms and values and internalize the norms of their group as a part of their character. So what we claim is not weather an individual has autonomy and free will to act differently. What we claim is that norms and social values are inseparable building blocks of an individual's being. Thus, the norms of her group become her norms and play a central role in her health decisions and behaviors. 
In daily life, there are additional reasons for deciding to comply with the norms of our social groups. People wish to be included with their friends and have a place within the group. To decide on the opposite of the social norm is always an option, but it is mostly avoided by the incentive of "to be somebody" within the social group, which means being respected and approved by the rest of the group. The individual has a place in that group when she complies with group the values. Another reason to comply with group values is the stringency of the norms. In some groups, the norms and values are so firm that rejecting these norms and deciding to act against the values, may possibly lead to social exclusion of the individual. People generally try to avoid social exclusion at any price.

In brief, social factors in addition to SES have a significant impact on the health status of individuals through three primary options. 1. The norms and values of the social group are absorbed by the individual and become central to self-identity and are thus incorporated in the character of the person. As a result, it becomes natural for the individual to decide and act in compliance with them. 2. Even if an individual does not internalize all of the norms and values of her group, the risk of social exclusion may be so high that she avoids opposing them. 3. People also comply with norms and values for the sake of having respect, approval and acceptance by their community.

We can explicitly see that being born into a social group is an unchosen feature. The social norms and values of the particular society have an enormous impact on the health status of individuals beyond their control. In the first option, it is impossible for the individual to act against the norms and values as they are a fundamental part of their being which makes it beyond individuals control also.

Our proposition about the second and third options may be defeated by Roemer's approach. Roemer describes a mechanism by which to distribute the personal and social responsibility between both the individual and the social group to which she belongs. Being aware of different social behavioral patterns among groups such as smoking, he offered to distinguish the average smoking rate of the individuals' group. He suggested that belonging to one group or the other is beyond one's control but how she fares compared to other members of the group is her responsibility. Therefore, in her group, the median smoker is assigned as the zero point. Those who smoke more than the median will have to bear the burdens of their risky behavior $(2,17)$.

Although Roemer's proposal seems plausible at first sight, it has a big problem which Norman Daniels has pointed out. Daniels claimed that "there seems to be something counterintuitive about letting responsibility to be sensitive to what others do. For example, since skiing is more common among rich people, the approach would imply that a poor person is more responsible for his broken leg in a skiing accident than is a rich person" (9). Also Roemer's proposal does not address the internalization of the social norms and values and the impossibility of acting against them, which I defined as the first option earlier. In addition, Roemer's view has a disadvantage of practicality, which I deliberately left out of this discussion.

The second group of unchosen features consists of the SES and social determinants of health. The fundamental causal theory and the arguments considering the social determinants of health explicitly indicate that these factors affect the actual health status of individuals beyond their control. These factors begin to sow the seeds of ill-health from the moment of birth or even before birth. Ending up with a disease is not caused by an instant decision, but a consequence of life-style pursued through a lifespan (9). The life-style is not only determined by the choices of individual's. Most of the time, life-style is also determined by social factors which are beyond individual's control. So, we can reconsider the first proposition of Luck Egalitarians; "the inequalities deriving from unchosen features of peoples' circumstances are unjust and therefore should be compensated for". As we have concluded that the mentioned social factors are among the unchosen factors so they should be compensated for as well.

Up to now, we have discussed what unchosen social features may be. Our second argument is about the chosen. Economists claim that our choices reveal our preferences; that is to say, if an individual has $\mathrm{X}$ amount of budget and spends it on A rather than $\mathrm{B}$, then this choice of her reveals her preference for B. This is called the "revealed preference theory" and is widely used for welfare analysis. This theory was basically developed to determine what is good for the population as a whole or to understand what people believe will aggregate their welfare. Thus, it is a theory to do welfare analysis to identify the most feasible resource allocation (18). Nevertheless this theory proposes an idea about human preference which states; 'when an individual makes a choice among possible goods, this implies that she deliberately wants that good along with all outcomes of that good'. That means when the individual chooses to smoke, she deliberately chooses the short-term and long-term outcomes of that choice, which may be pleasure and relief of stress and coronary heart disease or lung cancer, respectively. This proposition is plausible for the Luck Egalitarians.

On the other hand, we can think of situations which do not reveal the individual preference. There may be some barriers which affect a preference of one choice over another. These may be personal barriers like limited access to other options or lack of complete information regarding the choice. Social barriers are legislations, group membership, group norms, values and traditions. Also some psychological barriers may play an 
important role. Many of us may have heard a smoker saying "I wish I did not smoke". This is an example of a situation when the preference does not reveal the actual desire, but where the individual cannot avoid the temptation. This example may be tossed aside as an issue of psychiatry by claiming that it refers to addiction. Although addiction may be present, it still reveals an inexactitude of revealed preference theory.

This inexactitude is defined as a group of internalities by behavior economists to point out the "psychological barriers between intention and action" (18). The internalities may be a lack of self-control, limited attention, limited cognitive capacity or lack of understanding. These internalities correlate with the personal barriers but leave out the social ones which are defined in another set called externalities. Although the behavioral economists focus on internalities more, I would say it would be a big drawback if we leave the social barriers aside.

In this context, there is another important matter, which the behavior economists call "the hyperbolic discounting behavioral model". It suggests that the "preferences of individuals are inconsistent over time" (18). This model references the tradeoff between the preferences of short-term self and the long-term self. Although the smoking example fits well here, there are many other examples in daily life. Many people sign up for the gym but find a valid excuse not to exercise every time they are supposed to go to the gym. If signing up for the gym revealed their preference then how do we explain the infinitive excuses for not going to the gym? Behavioral economists say, to sign up for gym was the choice of the long-term self, while making up excuses and watching TV on the couch with a bowl of pop-corn is a choice of the short-term self. There is a constant tradeoff between current and future utility. The individual is basically saying "I do want the outcomes of exercising but now I want the pleasure of relaxing in front of TV". This trade off can be influenced by incentives such as lowering health insurance premiums for gym members or non-smokers. This means that the decision-making process of an individual may be influenced by "nudges". When these "nudges" come and touch their magic wand the individual's choice and actions may be diverted $(19,20)$.

All of these arguments point to additional ideas which are important to our discussion. First, the revealed preference theory does not work all of the time. We cannot be sure whether a current preference reflects the real choice of the individual or not. Second, the individual may choose another option if she could avoid personal and social barriers or if she is nudged towards one of the options. Third, the decisions of individuals are not immutable. People change their minds and decide to act in another way because of the influence of variables such as new information, changed social circumstances or gained experience. Thus, the decision-making process is not an only internal process of the individual mind but is very much in contact with the social environment which makes it implausible to hold the individual completely responsible for the current consequences of her past decisions. A side conclusion to this discussion may be that although there is proven evidence that individual choices may be diverted towards healthy choices by using incentives, is it morally acceptable to omit those incentives in practice and simply let people stumble. This side conclusion may open a discussion on paternalism, which we have deliberately avoided to stay in the frame of the main discussion.

Our third argument against Luck Egalitarianism stems from their definition of causal relationship between responsibility and ill-health. Luck Egalitarians are more inclined to accept the final cause of problem as the major cause, which is quite deceptive. To explain our view let's think about an individual who acts rationally and avoids all the risk factors causing illhealth. However, despite all of her efforts, she develops diabetes. She takes her drugs regularly and checks her blood glucose as she is told; these acts make her a prudent person. One day she has to hurry to catch her son's school bus and delays her insulin injection. Her body reacts badly and she ends up in the emergency room. According to Luck Egalitarianism, she acted imprudently by choosing not to take her injection on time, which makes her responsible for her current health status. Thus, we owe her no help or health service. She has to undertake all of the burdens her of risky behavior. We do not agree with this conclusion. It seems unfair to blame an individual, who has been prudent throughout her life, for a decision which she had to make suddenly. Sometimes, daily life urges all of us to decide and act instantly and we do not have the opportunity to think exhaustively. To disregard all the prudent acts and judge individuals by their urgent and/or instant decisions do not seem plausible.

This example also leads to our fourth objection to Luck Egalitarianism. Luck Egalitarianism ignores the motives behind decisions. It would make no difference to a Luck Egalitarian whether the woman was running to catch the school bus or she was in a hurry to commit a crime. Luck Egalitarians see no connection between the motives and ends of the choices. The only perspective they are interested in is who to hold responsible for the undesirable ends of an action. This perspective overlooks the integrity of human character. Individuals do not act only with the motive of being prudent and avoiding risks for themselves; they value some other things such as helping each other, solidarity, valor or love. These values may lead them to decide and act in a way which is more beneficial to another person and more risky or harmful for the individual herself. The actions which are motivated by devotion are often considered to be imprudent from the point of view of the 
Luck Egalitarians. However, many virtuous people would understand and value these types of decisions. They may claim that considering motivation is essential, in contrast to the Luck Egalitarians view, demanding assistance for these individuals instead of penalizing them with the burden of their decisions' consequences.

Our last objections to Luck Egalitarianism are both the difficulty of implementing the theory and its being contradictory to principles of medical ethics. Medical decisions require promptness and acuteness. Usually, a medical professional does not have the time to investigate the personal history of a patient on the basis of prudent decision-making when she arrives at the emergency room with a heart attack. The medical response to her emergency should be made very quickly. On the other hand, even if there is enough time to explore how prudently the patient acted, does it make any difference to the medical professional on a moral basis? The medical professional's moral obligation is not to decide on who is responsible for the illness, but to decide on the most efficient way to save the patient's life. Luck Egalitarians ascribe a task to medical professionals, which is in contrast with medical ethical principles. The medical ethics principles include non-maleficence, beneficence, respect to autonomy and justice (21). To triage patients depending on who is entitled to treatment is contradictory. The triage in an emergency room or the prioritization in health has to take into consideration other factors such as needs, urgency, age, severity and so on. To determine who caused this problem does not enter into the ethical decision-making process of medical professionals.

\section{LUCK EGALITARIANISM and HEALTH CARE POLICIES}

The arguments against Luck Egalitarianism reveal the fact that the Luck Egalitarian view is very limited to lead practical policy implementations. The health impact of social factors which are beyond individual's control, the mutable character of choices which makes individual responsibility of preferences implausible, weak causality between one time decisions and ill-health, ignorance of motives behind the decisions, contradictory position of the theory to medical ethics principles and impracticality of weighting degrees of individual choice in the context of a medical emergency are the main components of this impracticality.

Apart from the impracticality, health policies arising from Luck Egalitarian view lead to consequences in respect to patients and health service providers. Those patients who are considered imprudent may be asked to pay more for health services or they may receive low quality or old technology treatment; some may even have no access to particular health services due to giving priority to others for scare medical interventions (22). On the other hand, health service providers are urged to classify their patients and sub value the imprudent in respect to the prudent patients. This would force them to act against medical ethical principles such as respect to autonomy, justice and giving no harm (22).

However, we have recently seen some implications of Luck Egalitarianism in health services. These may be considered in two main titles: 1) the provisions which make the individual to make up for her imprudent choices, and 2) to nudge individuals to make prudent choices.

The provisions to urge the imprudent to make up for her choices work either by putting the financial burden of the health services on the individual or not giving precedence to her for the health services she needs. Giving priority to prudent individuals when more than one individual needs the same medical intervention is mostly discussed in the context of organ transplantation or heart surgery. Practical constrains to determine the extent of the imprudent decision on the actual health status is the major limitation for both provisions. However, private health insurers have overcome this practical difficulty to some extent by making a risk assessment regarding lifestyle choices of the individual and determining her premiums depending on the outcome of the assessment. For example, an individual who smokes or who is obese is subject to higher premiums for health insurance. Regarding public health insurance, putting additional taxes to tobacco or alcoholic drinks is a common policy of the single payer systems like Turkish health system. We should note that this approach does not cover all imprudent choices with health risks (22). The risky behaviors such as extreme sports or illegal habits like drug addiction are not subject to taxes by nature. Besides, the motive behind the addition taxes for imprudent/ unhealthy choices is not necessarily to establish equality that luck egalitarians ask for. Thus, they may hardly be considered health finance policy implications of luck egalitarianism. Furthermore, these policies may be considered to damage the egalitarian view as not all smokers or obese end up with the need for high health expenditures.

To encourage individuals to make prudent choices is an implication which is gaining popularity in health care policies. Health promotion policies are strengthened by prompts to facilitate healthier choices. Lower health insurance premiums offered for individuals who get screening tests for chronic diseases or giving up smoking are methods preferred by public or private health insurance companies. Sparing lanes for bicycles, shrinking the portions of soda drinks or offering salad as an alternative to French fries in combo meals are nudges of this kind. Prompts offer a holistic view which considers 
health policy as an integrated part of social policies and may help to end up with a healthier population and lower health expenditure. However, despite the fact that prompts may lead to more prudent health choices, they may hardly be considered as policies emerging from luck egalitarian view.

\section{CONCLUSION}

Luck Egalitarianism grounds the distributive justice of health systems on individual responsibility. By doing so, it claims that society owes assistance to those people whom face ill-health as a result of brute-luck, in other words by no fault of their own. Other people who develop health problems as a result of their imprudent choices are responsible for their own faults; thus, society owes them nothing. Because the practical impact of this theory on health financing may be huge, Luck Egalitarianism has frequently been discussed in recent literature. Many for and against arguments are raised regarding the Luck Egalitarianism theory, which are discussed in the preliminary section of this paper.

In the "new considerations" section of this paper, we raised our objections to the Luck Egalitarian Theory. Our first objection to Luck Egalitarianism is based on the narrow definition of health. Our next objection focuses on the concept of the inequalities deriving from social features beyond an individual's control. While Luck Egalitarianism refers to individual based disabilities such as low IQ, developmental problems, and genetic disorders, we propose including social features in this group. These are SES, access to social determinants of health, influences stemming from ethnic, religious and cultural norms and values. These social factors have an impact on the health status of people and are also beyond an individual's control. Thus, we should address these factors as we address other unchosen features. Our other objections are to the concept of mutable character of choices which makes an individual responsibility of preferences implausible, the weak causal relationship between a one-time decision and ill-health, the ignorance of motives behind decisions, and the impracticality of the said theory and contradictory nature of Luck Egalitarianism to medical ethical principles.

Taking into account all of the opposition to Luck Egalitarianism, it would be plausible to broaden the scope of social responsibility to avoid any exploitation of the needy and to support solidarity in society.

Peer-review: Externally peer-reviewed.

Author contributions: Concept - E.E.; Design - E.E.; Supervision - B.A.; Resource - E.E.; Materials - E.E.; Data Collection \&/or Process- ing - E.E., B.A.; Analysis \&/or Interpretation - E.E., B.A.; Literature Search - E.E., B.A.; Writing - E.E., B.A.; Critical Reviews - B.A.

Acknowledgements: This work is supported by Fogarty International Center / NIH grant (project number 1R25TW009248-01, KM Munir, PI) Fogarty International Center at the Boston Children's Hospital, Division of Developmental Medicine.

Conflict of Interest: No conflict of interest was declared by the authors.

Financial Disclosure: The authors declared that this study has received no financial support.

Editor-in-Chief's note: One of the authors of this article, Berna Arda is the member of the editorial board of Balkan Medical Journal. However, she did not take place at any stage on the editorial decision of the manuscript.

\section{REFERENCES}

1. Lippert-Rasmussen K. Justice and Bad Luck. The Stanford Encyclopedia of Philosophy 2009; Avaliable from: http://plato. stanford.edu/archives/fall2009/entries/justice-bad-luck.

2. Wikler D. Personal and Social Responsibility for Health. Ethics \& International Affairs 2002;16:47-55. [CrossRef]

3. Arneson RJ. Luck Egalitarianism and Prioritarianism. Ethics 2000;110:2. [CrossRef]

4. Arneson RJ. Luck Egaliratianism Interpreted and Defended. Phil Topics 2004;32:1-2. [CrossRef]

5. Anderson ES. What's the Point of Equality. Ethics 2005;109:287337. [CrossRef]

6. Brown A. Luck Egalitarianisn and Democratic Equality. Ethical Perspect 2005;12:293-339. [CrossRef]

7. Scheffler S. Choice, Circumstance, and the Value of Equality. Politics, Philosophy \& Economics 2005;4:5-28. [CrossRef]

8. Andersen MM. Health, personal responsibility, and distributive justice. Ph.D. thesis, Københavns Universitet, Det Humanistiske Fakultet, København 2013;15-28.

9. Daniels N. Just Health. 1st ed. Cambridge: Cambridge Unv. Press; 2008.

10. Link BG, Phelan JC. Social Conditions as Fundamantal Causes of Disease. J Health Soc Behav 1995;35:80-94. [CrossRef]

11. Link BG, Phelan JC, McKeown. The Idea That Social Condition Are Fundamental Causes of Disease. Am J Public Health 2002;92:730-2. [CrossRef]

12. WHO. Closing the gap in a generation Health equity through action on the social determinants of health. 2008. ISBN 9789241563703. Avaliable at: http://www.who.int/social_determinants/thecommission/finalreport/en/

13. Phelan JC, Link BG, Tehranifar P. Social Conditions as Fundamental Causes of Health Inequalities: Theory, Evi- 
dence and Policy Implications. J Health Soc Behav 2010;51: 28-30. [CrossRef]

14. Phelan JC, Link BG, Diez-Roux A, Kawachi I, Levin B. Fundamental Causes of Social Inequalities in Mortality: A Test of the Theory. J Health Soc Behav 2004;45:265-85. [CrossRef]

15. Marmot, MG. Fair Society Healthy Lives. Inequalities in Health Concepts, Measures, and Ethics'. 1st ed. Oxford University Press; 2013.

16. Whitehead, M. The Concept and Principles of Equity and Health. WHO Regional Office for Europe Copenhagen 1990.

17. Roemer JE. A pragmatic Theory of responsibility for the Egalitarian Planner. Philosophy and Public Affairs 1993;22: 146-66.
18. Margaret MC. Lecture on Behavioral economics and defining household well-being 2013 (December 2nd, Harvard University School of Public Health)

19. Wikler D. Persuasion and Coercion for Health: Ethical Issues in Government Efforts to Change Life. Milbank Mem Fund $Q$ Health Soc 1978;56:303-38. [CrossRef]

20. Hausman MD, Welch B. Debate: To Nudge or Not to Nudge. $J$ Political Philos 2010;18:123-36. [CrossRef]

21. Beauchamp TL, Childress JF. Principles of Biomedical Ethics. 6th ed. New York: Oxford University Press; 2009:241-8,33642,356-60.

22. Albertsen A, Knight C. A framework for luck egalitarianism in health and healthcare. J Med Ethics 2015;41:165-9. [CrossRef] 